\title{
Monitoramento da aquicultura em reservatórios continentais por meio do índice de estado trófico
}

\author{
Clauber ROSANOVA ${ }^{1 *}$, Emilio Sousa PINHO ${ }^{2}$, Flávia Tavares MATOS ${ }^{2}$, \\ Alberto AKAMA ${ }^{3}$, Guilherme Wolf BUENO ${ }^{4}$, Daniela Barbosa MACEDO ${ }^{1}$ \\ ${ }^{1}$ Instituto Federal do Tocantins, Palmas, TO, Brasil \\ ${ }^{2}$ Embrapa Pesca e Aquicultura, Palmas, TO, Brasil \\ ${ }^{3}$ Museu Paraense Emílio Goeldi, Belém, PA, Brasil. \\ ${ }^{4}$ Universidade Estadual Paulista, Registro - SP, Brasil \\ E-mail: clauber@ifto.edu.br
}

\begin{abstract}
Recebido em julho/2018; Aceito em novembro/2018.
RESUMO: A aquicultura é a atividade que mais cresce dentre os setores de produção de alimentos, porém, sua prática pode causar impactos ambientais no ambiente aquático, caso não haja um plano de monitoramento eficiente. $\mathrm{O}$ objetivo do presente trabalho foi avaliar o grau de trofia do ambiente utilizando o Índice de Estado Trófico (IET) em uma atividade aquícola de sistema de produção em tanques-rede no reservatório do Lajeado, Palmas, Tocantins na estação seca do ano. O monitoramento foi realizado no período de maio/2017 a agosto/2017 e envolveu a coleta de amostras para análises dos seguintes parâmetros de qualidade de água: fósforo total e clorofila-a. Paralelamente, houve a realização de coleta de dados de temperatura, turbidez, oxigênio dissolvido, condutividade, $\mathrm{pH}$ e sólidos totais dissolvidos. Os resultados do cálculo do Índice de Estado Trófico (IET) mostraram que a área em estudo durante os meses de maio e agosto apresentou-se predominantemente em graus eutrófico e hipereutrófico. O ponto controle também apresentou alto grau de trofia, indicando que o estado trófico do lago nas proximidades da área aquícola sofre forte influência de atividades antrópicas externas. Assim, os efeitos desta atividade a médio e longo prazo são difíceis de serem previstos, havendo a necessidade constante do monitoramento e controle da qualidade da água.
\end{abstract}

Palavras-chave: aquicultura, eutrofização, impacto ambiental, poluição, tanque rede.

\section{Monitoring of aquaculture in continental reservoirs using the trophic status index}

\begin{abstract}
Aquaculture is the fastest growing activity among food production sectors, however, its practice can cause environmental impacts, in case if a monitoring plan is not applied. The objective of the present study was to evaluate the trophic environment status using the Trophic State Index (TSI) in an aquaculture activity in a netcage system in the Lajeado reservoir, Palmas, Tocantins during the dry season. The monitoring was carried out from May / 2017 to August / 2017 and involved the water sampling for analysis of the following water quality parameters: total phosphorus and chlorophyll-a. At the same time, data were collected on temperature, turbidity, dissolved oxygen, conductivity, $\mathrm{pH}$ and total dissolved solids. The Trophic State Index (TSI) results showed that the area under study during the months of May and August was predominantly under a supereutrophic condition. It indicates that the lake trophic state in the aquaculture surrounding area is strongly influenced by external anthropogenic activities. Thus, the effects of this activity in the medium and long term are difficult to predict, so it's necessary to monitor and control the water quality.

Keywords: aquaculture, eutrophication, environmental impact, pollution, net cage.
\end{abstract}

\section{INTRODUÇÃO}

A grande disponibilidade de água em reservatórios de usinas hidrelétricas e a implantação de parques aquícolas no lago do Lajeado (Palmas/TO), no ano de 2015, propiciou ao Tocantins um grande potencial para produção de pescado em tanques-rede.

No contexto geral da produção de peixes em tanques-rede são necessárias técnicas de monitoramento ambiental para o acompanhamento da qualidade da água no decorrer da linha de cultivo (ALCÂNTARA et al., 2013). A produção de peixes em tanques-rede embora seja uma tecnologia com grande capacidade de produção, baixo investimento e de fácil instalação (ONO; KUBITZA, 2008), traz preocupações ambientais em relação ao modo de produção, sendo a eutrofização, oriunda da excreção de fezes dos peixes e o acúmulo de ração, um dos principais problemas (AZEVEDO et al., 2011)

De acordo com Smith; Schindler, (2009), o processo de eutrofização leva a alteração nas condições de qualidade de água, sabor, odor, turbidez, redução de oxigênio dissolvido e alteração da biodiversidade aquática.

No monitoramento de ambientes aquáticos, torna-se importante o conhecimento das condições de trofia dos corpos hídricos, a partir de limites calculados por indicadores correlacionados ao favorecimento da eutrofização, como o cálculo do Índice de Estado Trófico (IET) CETESB (2009a). O estado trófico de um corpo hídrico pode ser classificado como oligotrófico, mesotrófico, eutrófico, supereutrófico e hipereutrófico, de acordo com a classificação do estado trófico utilizado pela CETESB (2009a). 
Nesse contexto, o objetivo desse estudo foi avaliar o grau de trofia do ambiente em uma atividade aquícola de sistema de produção em tanques-rede, localizado no reservatório de Lajeado, Palmas - TO, especificamente no Parque Aquícola Sucupira, na estação seca do ano, utilizando-se como parâmetro o Índice de Estado Trófico de Lamparelli (2004).

\section{MATERIAL E MÉTODOS}

\section{1. Área de estudo}

A região de estudo delimitada neste trabalho foi a área de influência de produção de pescado em tanques-rede do Parque Aquícola Sucupira, localizada no reservatório do Lajeado a 15 $\mathrm{km}$ da cidade de Palmas, Tocantins, tendo coordenadas geográficas latitude $-10,0857$ e longitude $-48,3668$ em SIRGAS - Sistema de Referência Geocêntrico para as Américas (Seemüller; Drewes, 2000), conforme a Figura 1.

O reservatório do Lajeado ocupa uma área de $630 \mathrm{Km}^{2}$ de lâmina de água, representando $0,23 \%$ da área do estado do Tocantins, sendo construído basicamente para geração energética em 2001, com uma produção aproximada de 902,5 MW por dia. Além disso, há outros usos, como: abastecimento, irrigação, aquicultura, navegação, lazer entre outros.

Localizado em uma região de clima tropical, o reservatório do Lajeado está sujeito a mudanças em função do regime pluviométrico. Desta forma, a região do reservatório define-se em duas fases climáticas bem distintas: entres os meses outubro a março há o regime de chuvas e entres os meses de maio a setembro há restrições de chuvas, de acordo com os dados climatológicos apresentados pelo INMET (Instituto Nacional de Meteorologia) onde a normal climatológica e precipitação média em milímetros(mm) entre Janeiro/2017 e Agosto/2017 na cidade de Palmas (TO) foi de $115 \mathrm{~mm}$, com máxima de $240 \mathrm{~mm}$ em janeiro e 0 (zero) $\mathrm{mm}$ nos meses junho, julho e agosto respectivamente.

Pontos de Coleta - Reservatório de Lajeado, Palmas, Tocantins, Brasil.

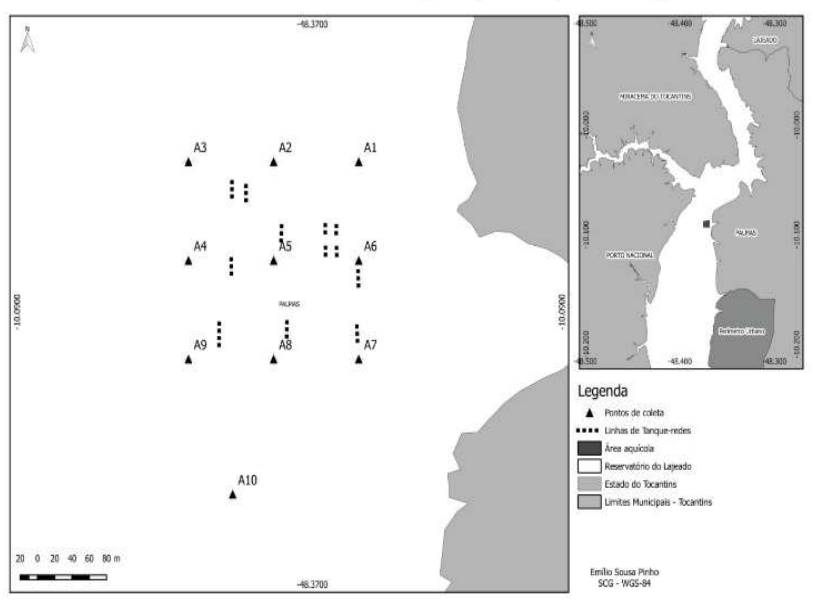

Figura 1. Pontos de coleta (A1 a A10) com as coordenadas em WGS84; monitoramento da área aquícola, reservatório de Lajeado, Palmas - TO e coordenadas geográficas dos pontos de amostragem.

\subsection{Coletas de dados}

As coletas de águas foram realizadas em 9 pontos equidistantes no período da manhã (08:00h), abrangendo toda área de produção de pescado nos tanques-rede, e 1 ponto de coleta que se encontra fora da área de produção como forma de controle. Foram feitas 4 campanhas entre maio-2017 e agosto-2017 uma a cada mês, no intuito de se determinar as concentrações de fósforo total $\left(\mu \mathrm{gL}^{-1}\right)$ e clorofila-a $\left(\mu \mathrm{gL}^{-1}\right)$, para os cálculos dos Índice de Estado Trófico segundo Lamparelli (2004).

As coletas de água foram feitas na lâmina superficial (30 $\mathrm{cm})$, com auxílio da garrafa de Van Dorn, a água coletada foi armazenada em frascos de polietileno de $1 \mathrm{~L}$ e mantidas refrigeradas a $4{ }^{\circ} \mathrm{C}$ e protegidas da luz. Posteriormente, as amostras foram transportadas para o laboratório de Saneamento Ambiental, do Instituto Federal do Tocantins para análise (fósforo total e clorofila-a). Parâmetros como temperatura $\left({ }^{\circ} \mathrm{C}\right), \mathrm{pH}$, condutividade $\left(\mathrm{mS} \mathrm{cm}^{-1}\right)$, oxigênio dissolvido $\left(\mathrm{mgL}^{-1}\right)$, sólidos totais $\left(\mathrm{mgL}^{-1}\right)$ e turbidez (NTU) foram analisados in loco mediante o uso de medidor multiparâmetros Horiba U-52G.

\subsection{Análises de qualidade de água}

2.3.1 Determinação da concentração de clorofila-a

A determinação de clorofila-a foi obtida por filtração de $0,5 \mathrm{~L}$ de amostra em membranas de fibra de vidro de $0,45 \mu \mathrm{m}$. A extração das clorofilas foi feita por meio de choque térmico com acetona a $90 \%$ e a maceração de cada amostra. Posteriormente, foram centrifugadas à $4000 \mathrm{rpm}$ por 10 minutos e armazenadas em ambientes refrigerado a $4^{\circ} \mathrm{C}$ por 24 horas para posterior análise. A leitura do sobrenadante foi feita com o auxílio de um espectrofotômetro em comprimento de onda $664 \mathrm{~nm}, 665 \mathrm{~nm}$ e $750 \mathrm{~nm}$ de acordo Standard Methods (1998). Os valores das concentrações de clorofila-a foram obtidos por meio da seguinte equação 1 :

$$
C l a\left(\frac{m g}{m^{3}}\right)=\frac{26,7 \times\left[644_{b}-665_{a}\right] \times V 1}{V 2 \times L} \quad(\text { Equação 1) }
$$

em que: $664_{b}$ : subtração da absorbância obtida em $\lambda=664 \mathrm{~nm}$ e $\lambda=$ $750 \mathrm{~nm}$; 665a: subtração da absorbância obtida em $\lambda=665 \mathrm{~nm}$ e $\lambda=$ $750 \mathrm{~nm}$ (densidade óptica após a acidificação); V1: Volume do extrato de acetona $(\mathrm{mL}) ; \mathrm{V} 2$ : Volume filtrado da amostra (Litros); L: Caminho ótico da cubeta $(\mathrm{cm})$.

\subsubsection{Determinação da concentração de fósforo total}

A quantificação de Fósforo total foi feita por meio de dois métodos: primeiro, digestão alcalina utilizando $0,210 \mathrm{mgL}^{-1} \mathrm{de}$ Persulfato de Potássio $0,210 \mathrm{mgL}^{-1} \mathrm{em}$ autoclave à $125^{\circ} \mathrm{C}$ por 25 minutos para determinação de todas as formas de fósforos presentes. Posteriormente, foi realizada a quantificação do fósforo total a partir do método do ácido ascórbico com concentração $17,6 \mathrm{gL}^{-1}$. As leituras das amostras foram feitas em espectrofotômetro a um comprimento de onda $880 \mathrm{~nm}$. A determinação da concentração de Fósforo total foi realizada por meio de curva de calibração, obtida pela correlação de concentrações padrões e os resultados de leituras, na qual, o resultado da equação da reta terá uma soma dos quadrados o mais próximo de $\mathrm{R}^{2}=1$, obtida na curva de calibração para fósforo total (MURPHY; RILEY, 1962; APHA, 1998).

\subsection{3. Índice de estado trófico (IET)}

O IET foi calculado com base na média aritmética da com centração das variáveis, clorofila-a e fósforo total, analisadas nos 10 pontos amostrais. Conforme Alves et al. (2012), o Índice do Estado Trófico (IET) é composto por dois outros Índices: Índice de Estado Trófico para o Fósforo e o Índice de Estado Trófico para a clorofila-a, usados por Lamparelli 2004 , sendo estabelecidos para ambientes idênticos. 
Para a determinação dos valores do IET (Tabela 1), conforme Lamparelli (2004) utilizam-se as seguintes equações:

$$
\begin{array}{ll}
\operatorname{IET}_{L}(C l a)=10 \times\left(6-\left(\frac{0,92-0,34(\ln (C l a))}{\ln 2}\right)\right) & \text { (Equação 2) } \\
\operatorname{IET}_{L}(P T)=10 \times\left(6-\left(\frac{1,77-0,42(\ln (P T))}{\ln 2}\right)\right) & \text { (Equação 3) } \\
I E T_{L}=\frac{I E T(P T)+I E T(C l a)}{2} & \text { (Equação 4) }
\end{array}
$$

em que: IETL $_{\mathrm{L}}$ Índice de Estado Trófico por Lamparelli (2004); PT: concentração de fósforo total medida na superfície da água, em g.L1; CL: concentração de clorofila total medida na superfície da água, em $\mu$ g.L.- ${ }^{-1}$ Ln: logaritmo.

Tabela 1. Valores do Índice de Estado Trófico e respectivas classes. Table 1. Values of the Trophic State Index and its classes.

\begin{tabular}{cc}
\hline Valor do IET & Classes do Estado Trófico \\
\hline$<47$ & ultraoligotrófico \\
$47-52$ & oligotrófico \\
$52-59$ & mesotrófico \\
$59-63$ & eutrófico \\
$63-67$ & supereutrófico \\
$>67$ & hipereutrófico \\
\hline
\end{tabular}

\section{RESULTADOS}

A Resolução CONAMA $n^{\circ} 357$, dispõe sobre a classificação dos corpos de água e diretrizes ambientais para o seu enquadramento. Os rios e reservatórios, no caso de não haver enquadramento, são considerados corpos d'água de classe 2, como é o caso do Reservatório do Lajeado. Dessa forma, os resultados obtidos e a discussão são baseados nos parâmetros e limites estabelecidos na classe 2.

Os parâmetros de temperatura, turbidez, oxigênio dissolvido, condutividade, $\mathrm{pH}$ e sólidos totais dissolvidos apresentam valores médios de $29,62 \pm 0,95^{\circ} \mathrm{C}, 6,11 \pm 2,23 \mathrm{NTU}$, $6,37 \pm 1,93 \mathrm{mgL}^{-1}, 0,074 \pm 0,01 \mathrm{mScm}, 7,17 \pm 0,33$ e $0,039 \pm 0,002$ $\mathrm{gL}^{-1}$, respectivamente, entre os meses de maio e agosto, conforme demonstram os gráficos da Figura 2.

Para o cálculo do índice de estado trófico, foram determinadas as concentrações dos parâmetros Clorofila "a" e fósforo total na estação seca, conforme demonstra a Tabela 2.

Tabela 2. Concentrações médias de Clorofila-a $\left(\mu \mathrm{gL}^{-1}\right)$ e fósforo total $\left(\mathrm{mgL}^{-1}\right)$ na área de estudo, durante a estação seca (de maio a agosto de 2017).

Table 2. Mean concentrations of Chlorophyll-a $\left(\mu \mathrm{gL}^{-1}\right)$ and total phosphorus $\left(\mathrm{mLL}^{-1}\right)$ in the study area during the dry season (May to August 2017).

\begin{tabular}{cc}
\hline Parâmetros & Concentração Média \\
\hline Maio & \\
Clorofila-a $\left(\mu \mathrm{gL}^{-1}\right)$ & $9,42 \pm 3,96$ \\
Fósforo Total $\left(\mathrm{mgL}^{-1}\right)$ & $0,35 \pm 0,07$ \\
Junho & $4,91 \pm 0,88$ \\
Clorofila-a $\left(\mu \mathrm{gL}^{-1}\right)$ & $0,10 \pm 0,01$ \\
Fósforo Total $\left(\mathrm{mgL}^{-1}\right)$ & \\
Julho & $2,60 \pm 0,81$ \\
Clorofila-a $\left(\mu \mathrm{gL}^{-1}\right)$ & $0,41 \pm 0,05$ \\
Fósforo Total $\left(\mathrm{mLL}^{-1}\right)$ & \\
Agosto & $9,71 \pm 1,38$ \\
Clorofila-a $\left(\mu \mathrm{gL}^{-1}\right)$ & $0,35 \pm 0,06$ \\
Fósforo Total $\left(\mathrm{mLL}^{-1}\right)$ & \\
\hline
\end{tabular}

A partir da Tabela 2 foram calculados os Índices de Estado Trófico segundo Lamparelli, (2004) no período de maio a agosto de 2017, conforme é demonstrado no Quadro 1. Para facilitar a visualização, os dados foram especializados e mapas foram produzidos com o auxílio do software gratuito Quantum Gis 2.18 (Figura 3).
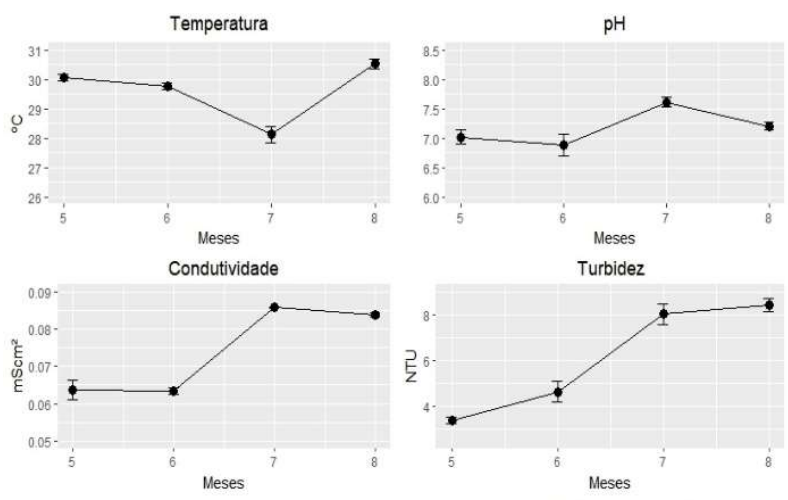

Oxigênio Dissolvido
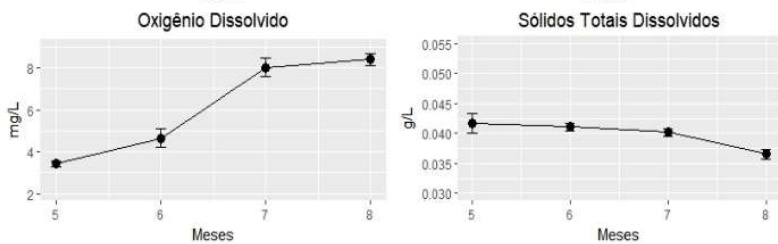

Figura 2. Temperatura, pH, Condutividade, Turbidez, Oxigênio Dissolvido e Sólidos Totais Dissolvidos obtidos na área de produção de pescado Sucupira, no reservatório de Lajeado, Palmas, Tocantins $(\mathrm{n}=9)$.

Figure 2. Temperature, $\mathrm{pH}$, Conductivity, Turbidity, Dissolved Oxygen and Total Dissolved Solids obtained in the Sucupira fish production area at the Lajeado Reservoir, Palmas, Tocantins $(n=9)$.

Quadro 1. Resultados da média dos índices de estados tróficos de clorofila-a e fósforo total e o grau do trofia do ambiente a partir dos valores aproximados de todos os pontos de amostragens no período de maio/2017 a agosto/2017.

Schema 1. Results of the average of the trophic states indexes of chlorophyll a and total phosphorus and the degree of the trophic environment from the approximate values of all the sampling points from May/2017 to August/2017.

\begin{tabular}{cccccc}
\cline { 1 - 4 } Ponto & Maio & Junho & Julho & Agosto & \\
\cline { 1 - 4 } A1 & 64 & 64 & 69 & 68 & \\
A2 & 66 & 66 & 68 & 70 & \\
A3 & 65 & 65 & 67 & 70 & ultraoligotrófico \\
A4 & 64 & 64 & 68 & 71 & oligotrófico \\
A5 & 65 & 65 & 66 & 70 & mesotrófico \\
A6 & 64 & 64 & 66 & 70 & eutrófico \\
A7 & 64 & 64 & 66 & 70 & supereutrófico \\
A8 & 64 & 64 & 67 & 69 & hipereutrófico \\
A9 & 65 & 65 & 66 & 70 & \\
\hline
\end{tabular}

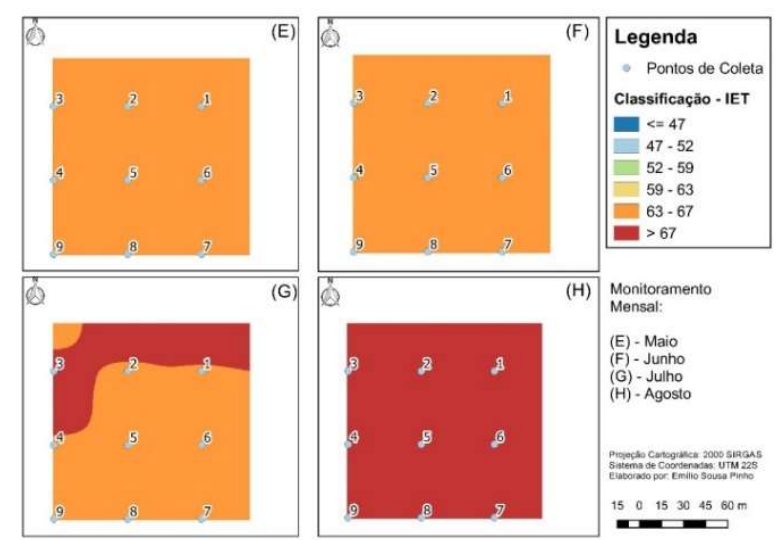

Figura 3. Perfil do estado trófico na área de estudo entre os meses de maio a agosto de 2017 (E, F, G, H).

Figure 3. Trophic state profile in the study area between May and August 2017 (E, F, G, H). 
Com relação ao ponto controle, os dados de clorofila "a", fósforo total e a determinação do índice de estado trófico foram organizados separadamente, conforme é demonstrado na Tabela 3.

Tabela 3. Concentrações de Clorofila-a $\left(\mu \mathrm{gL}^{-1}\right)$, fósforo total $\left(\mu \mathrm{gL}^{-1}\right)$ e o índice de Estado Trófico (IET) no ponto controle (A10) durante o período de janeiro a agosto de 2017.

Table 3. Concentrations of Chlorophyll-a $\left(\mu \mathrm{gL}^{-1}\right)$, total phosphorus $\left(\mu \mathrm{gL}^{-1}\right)$ and Trophic State index (EET) at the control point (A10) during the period from January to August 2017.

\begin{tabular}{cccc}
\hline Meses & Clorofila "a" & Fósforo total & IET \\
\hline maio & 4,5 & 0,09 & 64 \\
junho & 4,5 & 0,09 & 64 \\
julho & 3,1 & 0,42 & 67 \\
agosto & 9,7 & 0,4 & 70 \\
\hline
\end{tabular}

\section{DISCUSSÃO}

Considerando os parâmetros de qualidade de água durante a estação seca, a temperatura média da água foi de 29,62 $\pm 0,95$ ${ }^{\circ} \mathrm{C}$, o que favoreceu o desenvolvimento e desempenho de peixes tropicais via aceleração do metabolismo com consequente aumento da ingestão de alimentos (PEZZATO et al., 2004). De acordo com Kubtiza (2003) temperaturas da água entre $26^{\circ} \mathrm{C}$ a $30^{\circ} \mathrm{C}$ correspondem a valores ótimos para o cultivo de peixes. Segundo Marques (2006) no reservatório da Usina Hidrelétrica do Lajeado ocorrem variações de temperaturas entre $25^{\circ} \mathrm{C}$ e $31,70^{\circ} \mathrm{C}$ ao longo do ano.

Com relação à condutividade elétrica, os valores médios obtidos foram de $0,07 \pm 0,01 \mathrm{mS} / \mathrm{cm}$, resultados semelhantes aos observados por Peixoto (2007) em estudos na UHE Lajeado. A Resolução CONAMA 357/2005 não determina limites de tolerância específicos para cada parâmetro, porém, a CETESB (2009b) aponta, que valores para condutividade elétrica acima de $0,100 \mathrm{mS} / \mathrm{cm}$, indicam a possibilidade de entrada de esgoto no ambiente.

Os parâmetros de $\mathrm{pH}$ e turbidez apresentaram resultados médios dentro dos limites exigidos pela Resolução CONAMA $\mathrm{n}^{\circ} 357 / 05$ - pH 6,0-9,0 e turbidez menor e igual a $100 \mathrm{NTU}-$

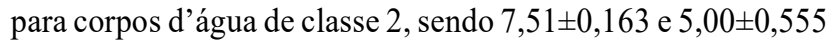
NTU, respectivamente. Peixoto (2007), observou em estudos realizados na UHE Lajeado valores de $\mathrm{pH}$ na faixa de 7,6 variando de ligeiramente alcalino a neutro, o que segundo Vinatea-Arana (1997) pode ser considerado com a faixa de $\mathrm{pH}$ adequada para produção de pescado, variando de 6,5 a 9,0 e que, valores de 4,0 e 11,0 (ácido e básico) são letais para vida aquática.

Os valores de oxigênio dissolvido e sólidos totais dissolvidos (STD) em alguns pontos apresentaram resultados fora do limite da Resolução CONAMA 357 nos meses de maio e junho, conforme o enquadramento de classe 2: oxigênio dissolvido menor ou igual a $5 \mathrm{mgO}_{2} \mathrm{~L}^{-1}$ e concentração máxima de STD de $0,0500 \mathrm{gL}^{1}$.

Peixoto (2007) e Marques (2006) em estudos na UHE Lajeado observaram valores diferentes de oxigênio dissolvido ao longo da estação seca, com concentração desse gás variando entre 6,74 mg/L e 8,60mg/L. De acordo com Prado (1999), a concentração de oxigênio dissolvido em um corpo hídrico pode ser usada para a determinação da qualidade da água. Quanto mais reduzida for a concentração de oxigênio dissolvido, mais poluído o curso d'água se encontra, influenciando diretamente na biodiversidade aquática. Os valores abaixo $\left(4,25 \mathrm{mgO}_{2} \mathrm{~L}^{-1}\right)$ do limite tolerado da concentração de oxigênio dissolvido no reservatório de Lajeado podem estar relacionados ao consumo de oxigênio pela degradação da quantidade excessiva de matéria orgânica ou possuir forte influência dos processos pluviométricos.

A concentração média de clorofila-a encontrada nos pontos de amostragem foi de $6,2 \mu \mathrm{g} / \mathrm{L}$, permanecendo dentro do valor tolerado pela Resolução do CONAMA 357/05, $(<30$ $\mu \mathrm{g} / \mathrm{L})$, para corpo hídrico enquadrado na classe 2 . O trabalho de Marques (2006) apontou médias próximas a 5,5 $\mu \mathrm{gCl}-\mathrm{aL}^{1}$ no período das chuvas na UHE Lajeado, enquanto Pereira (2002) observou concentrações de $12,78 \mu \mathrm{gCl}-\mathrm{aL}^{1}$ na fase de enchimento do reservatório.

Com relação ao fósforo total, as concentrações médias encontradas na área de influência do parque aquícola Sucupira se apresentaram acima do permitido na Resolução 357/05, para ambientes lênticos de água doce, classe $2(<0,030 \mathrm{mg} / \mathrm{L})$, sendo de $0,301 \mathrm{mg} / \mathrm{L}$. Neste caso, a concentração do fósforo pode ter sido influenciada tanto pela atividade da piscicultura como por atividades antrópicas externas (como lançamento de efluentes domésticos e agricultura), dificultando a identificação do principal contribuinte de fósforo no sistema. $\mathrm{O}$ fósforo está diretamente ligado à produtividade da condição de um reservatório e tem sido apontado com o principal responsável pela eutrofização artificial (ESTEVES, 1998; BUZELLI; CUNHA SANTINO, 2013). Peixoto (2007) calculou a concentração máxima de fósforo afluente admissível por ano para manter o ambiente do reservatório da UHE Lajeado mesotrófico e concluiu que haveria necessidade de reduzir a carga afluente de fósforo de $31.225 \mathrm{~kg}$ P/ano para $3.148 \mathrm{~kg} /$ ano, ou seja, uma redução de 28.077 kg P/ano.

Com relação aos dados obtidos por meio do cálculo do Índice de Estado Trófico (IET), no período de maio e junho, quando foram registrados índices pluviométricos abaixo de 20 $\mathrm{mm}$, todos os pontos localizados na área de influência do Parque Aquícola Sucupira, apresentaram índices de estado trófico classificados como eutróficos.

Nos meses julho e agosto, quando não houve registro de chuva, o índice do estado trófico predominante na área durante o mês de julho foi classificado como eutrófico, com alguns pontos classificados como hipereutrófico. Já em agosto, todos os pontos foram classificados como hipereutróficos.

Pena et al. (2004), realizaram campanhas de monitoramento em 16 pontos amostrais ao longo deste reservatório, durante os anos de 2002 e 2003, onde foram quantificados os parâmetros de transparência, clorofila-a e fósforo total. Os autores observaram que o reservatório da UHE Lajeado apresentou características mesotróficas a partir do cálculo do índice de estado trófico pelo método de Toledo (1990), durante todo o período de estudo e sugeriram que as oscilações nos valores do cálculo de IET de transparência podem estar relacionadas à interferência de sólidos totais que implicam na condição do grau de trofia do ambiente.

Mallasen et al. (2012), avaliaram a condição da qualidade da água em um sistema de piscicultura em tanques-rede no Reservatório de Ilha Solteira São Paulo e concluíram que a produção de peixes na região provoca baixo impacto no ecossistema aquático. O reservatório demonstrou ser eficiente na capacidade de assimilação da carga de nutrientes proveniente de produção de pescado.

\section{CONCLUSÕES}

De maneira geral, as variáveis limnológicas (temperatura, condutividade, turbidez, oxigênio dissolvido, $\mathrm{pH}$ e sólidos 
totais dissolvidos), com exceção do fósforo total, apesar das pequenas variações de oxigênio e sólidos totais, estão de acordo com dos padrões recomendados pela Resolução CONAMA 357/05.

No período da seca, pelo fato de não haver a diluição de nutrientes devido à escassez de chuvas, ocorre aumento considerável na concentração de fósforo na água, levando a um estado hipereutrófico. Paralelamente, da mesma forma que ocorreu com os outros pontos, o índice também se apresentou alto no ponto controle (A10), nas classes de eutrófico e hipereutrófico. Esse fato indica que a aquicultura não é uma atividade impactante e que o lago apresenta naturalmente altos índices de fósforo, principalmente na seca, sofrendo influência também de atividades antrópicas, como o lançamento de efluentes e agricultura.

Os efeitos da atividade são difíceis de serem previstos a longo prazo, bem como o comportamento do reservatório mediante aumento da produção de peixes em tanques-rede, por isso, é fundamental que seja executado um programa de monitoramento constante da qualidade de água.

\section{AGRADECIMENTOS}

Os agradecimentos a Universidade Federal do Tocantins através do seu Programa de Pós-Graduação em Ciências do Ambiente, Faculdade Católica do Tocantins (Laboratório de Saneamento Ambiental) e ao Instituto de Educação Ciência e Tecnologia do Tocantins, Campus Palmas.

\section{REFERÊNCIAS}

ALCÂNTARA, E.; CURTARELLI, M.; OGASHAWARA, I.; STHECH, J.; SOUZA, A. A system for environmental monitoring of hydroelectric reservoirs in Brazil. Revista Ambiente \& Água, Taubaté, v. 8, n. 1, p. 6-17, 2013.

ALVES, I. C. C.; El-ROBRINI, M.; SANTOS, M. L. S.; MONTEIRO; S. M.; BARBOSA, L. P. F.; GUIMARÃES, J. T. F. Qualidade das águas superficiais e avaliação do estado trófico do Rio Arari (Ilha de Marajó, norte do Brasil). Acta Amazônica, Manaus, v. 42, n. 1, p. 115-124, 2012. http://dx.doi.org/10.1590/S004459672012000100014

APHA_AMERICAN PUBLIC HEALTH ASSOCIATION. Standard methods for the examination of water and wastewater. 20. ed. Washington: American Public Health Association - American Water Works Association - Water Environmental Federation, 1998. 1220 p.

AZEVEDO, P. A.; PODEMSKI, C. L.; HESSLEIN, R. H.; KASIAN, S. E. M; FINDLAY, D. L.; BUREAU, D P. Estimation of waste outputs by a rainbow trout cage farm using a nutritional approach and monitoring of lake water quality. Aquaculture, Amsterdam, v. 311, p. 175 186 , 2011.

DOI: http://dx.doi.org/10.1016/j.aquaculture.2010.12.001

BRASIL. Lei No 9433/1997, de 08 de janeiro de 1997 "Institui a Política Nacional de Recursos Hídricos, cria o Sistema Nacional de Gerenciamento de Recursos Hídricos, regulamenta o inciso XIX do art. 21 da Constituição Federal, e altera o art. $1^{\circ}$ da Lei $n^{\circ} 8.001$, de 13 de março de 1990, que modificou a Lei $n^{\circ} 7.990$, de 28 de dezembro de 1989.". Diário Oficial da União Federativa do Brasil - DOU, Brasília, DF, 09 de janeiro de 1997.

BRASIL, Resolução n 357, de 17 de março de 2005 - "Dispõe sobre a classificação dos corpos de água e diretrizes ambientais para o seu enquadramento, bem como estabelece as condições e padrões de lançamento de efluentes, e dá outras providências. ”. Conselho Nacional de Meio Ambiente, Brasília, DF, 17 de março de 2005. Disponível em: $<$ http//:www.mma.gov.br $>$. Acesso em: 28 de setembro de 2016.

BUZELLI, G. M.; CUNHA-SANTINO, M. B. Análise e diagnóstico da qualidade da água e estado trófico do reservatório de Barra Bonita (SP). Revista Ambiente \& Água, Taubaté, v. 8, n. 1, p. 186-205, 2013. DOI: http://dx.doi.org/10.4136/ambi-agua.930

CETESB_COMPANHIA DE TECNOLOGIA E SANEAMENTO AMBIENTAL. Relatório de qualidade das águas interiores do estado de São Paulo 2008. São Paulo: Série Relatórios-Secretaria de Estado do Meio Ambiente. 2009a. 531 p. v. 1

CETESB_COMPANHIA AMBIENTAL DO ESTADO DE SÃO PAULO (CETESB). Variáveis de qualidade de água. 2009b. Disponível em: $<$ http://www.cetesb.sp.gov.br/Agua/rios/variaveis.asp\#tra nsparencia>. Acesso em: 20 de outubro de 2016.

KUBITZA, F. Qualidade da água no cultivo de peixes e camarões. $1^{\mathrm{a}}$ ed. Jundiaí. 2003. $229 \mathrm{p}$

LAMPARELLI, M. C. Grau de trofia em corpos d'gua do Estado de São Paulo: avaliação dos métodos de monitoramento. 2004. 207f. Tese (Doutorado em Ciências) - Universidade de São Paulo, São Paulo, 2004.

MALLASEN, M.; CARMO, C. F.; TUCCI, A.; BARROS, H. P.; ROJAS, N. E. T.; FONSECA, F. S.; YAMASHITA, E. Y. Qualidade da água em sistema de piscicultura em tanques-rede no reservatório de Ilha Solteira, SP. Boletim do Instituto de Pesca, São Paulo, v. 38, n. 1, p. 15-30, 2012.

MARQUES, A. K. Análise da diversidade fitoplanctônica no reservatório da Usina Hidroelétrica Luis Eduardo Magalhães, no médio Tocantins - TO: estrutura da comunidade, flutuações temporais e espaciais. 2006. 158f. Dissertação (Mestrado em Ciências do Ambiente) Universidade Federal do Tocantins, Palmas, 2006.

ONO, E.A.; KUBITZA, F. Cultivo de peixes em tanques rede. 3.ed. Jundiaí: E. Ono, 2003. 112p.

PEIXOTO, R. H. P. B. Efeitos da implantação do reservatório da Usina Hidrelétrica Luis Eduardo Magalhães sobre a qualidade da água do rio Tocantins (TO, Brasil). Rio de Janeiro, 2007. 222f. Tese (Doutorado) - Instituto de Geociências, Universidade Federal do Rio de Janeiro.

PENA, L.; FERREIRA, C.; ALMEIDA, M. Comportamento dos índices do estado trófico de Carlson (IET) e modificado (IETM) no reservatório da UHE Luís Eduardo Magalhaes. Tocantins-Brasil. In: Congreso Interamericano de Ingeniería Sanitaria y Ambiental, 29., San Juan, 2004. Anais... San Juan: AIDIS, 2004. p. 1- 6.

PEREIRA, V. L. R. A limnologia e o gerenciamento integrado do reservatório da Usina Hidrelétrica Luis Eduardo Magalhães - UHE Lajeado, Tocantins. 2002. 284 f. Tese (Doutorado em Ciências da Engenharia Ambiental) - Universidade de São Paulo, São Carlos, 2002.

PEZZATO, L. E.; BARROS, M. M.; FRACALOSSI, D. M.; CYRINO, J. E. P. Nutrição de peixes. In: CYRINO, J. E. P.; URBINATI, E. C.; FRACALOSSI, D. M.; CASTAGNOLli, N. (Org.). Tópicos especiais em

Nativa, Sinop, v. 7, n. 3, p. 262-267, mai/jun. 2019. 
piscicultura de água doce tropical intensiva. São Paulo: TecArt, 2004. p. 75-170

PRADO, R. B. Influência do uso e ocupação do solo na qualidade da água: estudo no médio rio Pardo - SP (período de 1985 a 1997). 1999. 209f. Dissertação (Mestrado em Ciências da Engenharia Ambiental) Escola de Engenharia de São Carlos, Universidade de São Paulo, São Carlos. 1999.

SEEMÜLlER, W.; DREWES, H. Annual Report 1999 of RNAAC SIRGAS. Pasadena: IGS 1999 Technical Reports - IGS CB - JPL Pasadena, 2000.

SMITH, V. H.; SCHINDLER, D.W. Eutrophication science: where do we go from here?. Trends in Ecology and Evolution, Amsterdam, v. 24, n. 4, p. 201-207, 2009. DOI: https://dx.doi.org/10.1016/j.tree.2008.11.009

TOLEDO JR., A. P. Informe preliminar sobre os estudos para a obtenção de um índice para avaliação do estado trófico de reservatórios de regiões quentes tropicais. São Paulo: CETESB, 1990. 12 p.(Relatório Interno CETESB)

VINATEA-ARANA, L. Princípios químicos de qualidade da água em aqüicultura. Florianópolis: Editora da UFSC. 1997. $166 \mathrm{p}$. 